\title{
Impact of Serum Uric Acid Levels on Coronary Plaque Stability Evaluated Using Integrated Backscatter Intravascular Ultrasound in Patients with Coronary Artery Disease
}

\author{
Kaoru Ando ${ }^{1}$, Hiroki Takahashi ${ }^{1}$, Tetsu Watanabe ${ }^{1}$, Hyuma Daidoji ${ }^{2}$, Yoichiro Otaki ${ }^{1}$, Satoshi Nishiyama ${ }^{1}$, \\ Takanori Arimoto ${ }^{1}$, Tetsuro Shishido ${ }^{1}$, Takehiko Miyashita ${ }^{3}$, Takuya Miyamoto ${ }^{1}$ and Isao Kubota ${ }^{1}$ \\ ${ }^{1}$ Department of Cardiology, Pulmonology, and Nephrology, Yamagata University School of Medicine, Yamagata, Japan \\ ${ }^{2}$ Department of Cardiology, Yamagata Prefectural Central Hospital, Yamagata, Japan \\ ${ }^{3}$ Department of Cardiology, Tohoku Pharmaceutical University, Miyagi, Japan
}

\begin{abstract}
Aim: Because the prevalence of hyperuricemia is lower in females than in males, the association between hyperuricemia and cardiovascular disease has been frequently reported in females. Increased serum uric acid levels are associated with the presence of cardiovascular risk factors such as hypertension, renal dysfunction, insulin resistance, and metabolic syndrome. However, it is controversial whether hyperuricemia is an independent risk factor for coronary artery disease in both the genders. The purpose of this study was to investigate the relationship between serum uric acid levels and coronary plaque components assessed using integrated backscatter intravascular ultrasound (IB-IVUS) in males and females.

Methods: In total, 385 patients (298 males and 87 females) who underwent percutaneous coronary intervention using IB-IVUS were divided into three groups in each gender according to their serum uric acid levels. We characterized tissue from coronary plaques in culprit lesions.

Results: Serum uric acid levels significantly correlated with percent lipid volume $(r=0.37)$ and inversely correlated with percent fibrous volume $(r=-0.35)$. Multivariate analysis showed that the uric acid level was independently associated with lipid-rich plaques (odds ratio $2.43,95 \%$, confidence interval $1.75-$ 3.47). The prevalence of lipid-rich plaques increased with increasing uric acid levels in both genders. Conclusion: Increased serum uric acid levels were associated with larger lipid content plaques in both genders.
\end{abstract}

\section{See editorial vol. 23: 905-907}

Key words: Uric acid, Intravascular ultrasound, Plaque component

\section{Introduction}

Several epidemiological studies have reported that hyperuricemia, the presence of excess uric acid in the blood, is associated with cardiovascular disease ${ }^{1,2}$. Serum uric acid levels are affected by body mass index, physique, kidney dysfunction, and hypertension.

Address for correspondence: Tetsu Watanabe, Department of Cardiology, Pulmonology, and Nephrology, Yamagata University School of Medicine, 2-2-2 Iida-Nishi, Yamagata, 990-9585, Japan

E-mail: tewatana@med.id.yamagata-u.ac.jp

Received: November 13, 2015

Accepted for publication: January 25, 2016
Therefore, it is controversial whether hyperuricemia is an independent risk factor for coronary atherosclero$\mathrm{sis}^{3)}$. The effect of hyperuricemia on coronary atherosclerosis evaluated by intravascular ultrasound (IVUS) or coronary computed tomographic angiography has been reported ${ }^{4-6}$. However, it remains to be determined whether serum uric acid levels are associated with coronary plaque components.

In general, serum uric acid levels are higher in male than female populations. Estrogen has been reported to promote the clearance of uric $\mathrm{acid}^{7)}$. Serum uric acid levels increase after menopause in females but are still lower than those in males. Females have low risks for being overweight and high alcohol intake, which 
Table 1. Patient characteristics

\begin{tabular}{|c|c|c|c|c|c|c|c|c|c|c|}
\hline & \multirow{2}{*}{$\begin{array}{c}\text { All } \\
(n=385)\end{array}$} & \multicolumn{4}{|c|}{ Male } & \multicolumn{4}{|c|}{ Female } & \multirow{2}{*}{$\begin{array}{l}\text { Interaction } \\
\mathrm{P} \text { with } \\
\text { gender }\end{array}$} \\
\hline & & $\begin{array}{c}\text { T1M } \\
(n=100)\end{array}$ & $\begin{array}{c}\text { T2M } \\
(n=97)\end{array}$ & $\begin{array}{c}\text { T3M } \\
(n=101)\end{array}$ & $P$ value & $\begin{array}{c}\mathrm{T} 1 \mathrm{~F} \\
(n=29)\end{array}$ & $\begin{array}{c}\mathrm{T} 2 \mathrm{~F} \\
(n=29)\end{array}$ & $\begin{array}{c}\text { T3F } \\
(n=29)\end{array}$ & $P$ value & \\
\hline Age, years & $69.1 \pm 10.9$ & $69.5 \pm 8.8$ & $65.5 \pm 11.7^{*}$ & $68.7 \pm 11.6$ & 0.024 & $72.6 \pm 7.8$ & $73.6 \pm 11.1$ & $74.1 \pm 10.1$ & 0.836 & 0.286 \\
\hline Body mass index, $\mathrm{kg} / \mathrm{m}^{2}$ & $23.6 \pm 3.2$ & $22.9 \pm 2.8$ & $23.9 \pm 3.6$ & $24.4 \pm 3.1^{*}$ & 0.011 & $22.9 \pm 3.6$ & $22.7 \pm 3.1$ & $24.4 \pm 2.9$ & 0.171 & 0.431 \\
\hline Hypertension & $278(72 \%)$ & $58(59 \%)$ & $71(73 \%)$ & $77(76 \%)^{\dagger}$ & 0.017 & $22(76 \%)$ & $24(83 \%)$ & $27(93 \%)$ & 0.174 & 0.624 \\
\hline Diabetes mellitus & $161(42 \%)$ & $46(46 \%)$ & $44(45 \%)$ & $34(33 \%)$ & 0.133 & $11(38 \%)$ & $8(28 \%)$ & $19(65 \%)^{8}$ & 0.010 & 0.002 \\
\hline Dyslipidemia & $246(64 \%)$ & $53(53 \%)$ & $60(62 \%)$ & $75(74 \%)^{\dagger}$ & 0.026 & $21(72 \%)$ & $18(62 \%)$ & $20(69 \%)$ & 0.693 & 0.200 \\
\hline Current smoking & $89(23 \%)$ & $27(27 \%)$ & $32(33 \%)$ & $28(27 \%)$ & 0.606 & $1(3 \%)$ & $1(3 \%)$ & 0 & 0.439 & 0.471 \\
\hline ACS & $130(33 \%)$ & $41(41 \%)$ & $21(22 \%)^{\dagger}$ & $35(35 \%)$ & 0.013 & $11(38 \%)$ & $11(38 \%)$ & $7(24 \%)$ & 0.426 & 0.131 \\
\hline LDL cholesterol, mg/dl & $100.4 \pm 33.9$ & $95.3 \pm 33.8$ & $96.9 \pm 35.0$ & $102.3 \pm 32.3$ & 0.301 & $108.8 \pm 33.7$ & $107.3 \pm 35.0$ & $106.0 \pm 34.3$ & 0.955 & 0.620 \\
\hline HDL cholesterol, mg/dl & $49.3 \pm 11.9$ & $50.1 \pm 11.0$ & $47.3 \pm 11.9$ & $48.3 \pm 12.1$ & 0.239 & $52.1 \pm 15.1$ & $52.6 \pm 11.9$ & $50.6 \pm 9.4$ & 0.834 & 0.611 \\
\hline $\mathrm{eGFR}, \mathrm{ml} / \mathrm{min} / 1.73 \mathrm{~m}^{2}$ & $72.7 \pm 24.1$ & $82.2 \pm 22.6$ & $75.0 \pm 21.9$ & $63.2 \pm 18.3^{\dagger \S}$ & $<0.001$ & $82.3 \pm 34.1$ & $69.1 \pm 22.7$ & $59.2 \pm 23.9^{\dagger}$ & 0.011 & 0.681 \\
\hline Uric acid, mg/dl & $5.5 \pm 1.4$ & $4.2 \pm 0.6$ & $5.6 \pm 0.3$ & $7.2 \pm 1.0$ & $<0.001$ & $3.7 \pm 0.7$ & $4.9 \pm 0.3$ & $6.6 \pm 1.1$ & $<0.001$ & 0.430 \\
\hline LVEF, \% & $59.6 \pm 12.6$ & $57.4 \pm 12.6$ & $58.9 \pm 12.9$ & $60.9 \pm 12.8$ & 0.209 & $59.3 \pm 11.9$ & $64.3 \pm 11.2$ & $59.2 \pm 11.9$ & 0.256 & 0.257 \\
\hline \multicolumn{11}{|l|}{ Concomitant medications } \\
\hline Statins & $181(45 \%)$ & $36(36 \%)$ & $53(55 \%)$ & $46(46 \%)$ & 0.072 & $9(31 \%)$ & $13(45 \%)$ & $17(59 \%)$ & 0.274 & 0.329 \\
\hline Anti-hyperuricemics & $58(14 \%)$ & $7(7 \%)$ & $14(14 \%)$ & $30(30 \%)^{\dagger \S}$ & $<0.001$ & $1(3 \%)$ & $1(3 \%)$ & $3(10 \%)$ & 0.453 & 0.868 \\
\hline Diuretics & $68(17 \%)$ & $9(9 \%)$ & $16(17 \%)$ & $19(19 \%)$ & 0.108 & $4(14 \%)$ & $5(17 \%)$ & $12(41 \%)^{* *}$ & 0.032 & 0.318 \\
\hline$\beta$ blockers & $174(43 \%)$ & $44(44 \%)$ & $45(46 \%)$ & $42(42 \%)$ & 0.793 & $16(55 \%)$ & $13(45 \%)$ & $8(28 \%)$ & 0.095 & 0.221 \\
\hline RAA inhibiters & $278(72 \%)$ & $71(71 \%)$ & $71(73 \%)$ & $70(69 \%)$ & 0.832 & $23(79 \%)$ & $20(69 \%)$ & $23(79 \%)$ & 0.577 & 0.494 \\
\hline
\end{tabular}

Data are expressed as n (\%) for categorical variables and mean \pm standard deviation for continuous variables. ${ }^{*} p<0.05$ vs T1, ${ }^{\dagger} p<0.01$ vs T1, ${ }^{\ddagger} p<$ 0.05 vs T2, ${ }^{\S} p<0.01$ vs T2.

ACS, acute coronary syndrome; LDL, low-density lipoprotein; HDL, high-density lipoprotein; eGFR, estimated glomerular filtration rate; LVEF, left ventricular ejection fraction; RAA, renin angiotensin aldosterone system

are associated with elevated serum uric acid levels ${ }^{8)}$. Moreover, it was reported that the impact of hyperuricemia on cardiovascular disease is greater in females than in males ${ }^{9,10)}$. Therefore, we investigated the association between serum uric acid levels and cardiovascular disease by sex.

Integrated backscatter (IB)-IVUS has recently been developed to analyze coronary plaque tissue characteristics more precisely than gray-scale IVUS ${ }^{11,12)}$. Coronary plaque components analyzed using IB-IVUS were reported to be well correlated with histological findings ${ }^{12)}$. Lipid-rich plaque evaluated using IB-IVUS was associated with future cardiovascular events ${ }^{13)}$ and no re-flow phenomenon during percutaneous coronary intervention $(\mathrm{PCI})^{14)}$. In the present study, we investigated the impact of serum uric acid levels on coronary plaque components, as assessed by IB-IVUS in patients who underwent PCI.

\section{Materials and Methods}

\section{Study Population}

From July 2009 to November 2012, 401 patients underwent PCI using IB-IVUS in our hospital. Sixteen patients on hemodialysis were excluded, and the remaining 385 patients were enrolled in the study. All patients gave written informed consent. The protocol was approved by the institution's Human Investigation Committee. Procedures were performed in accordance with the Declaration of Helsinki.

\section{Measurement of Serum Uric Acid Levels}

Blood samples were obtained on admission to the hospital. The serum uric acid levels were determined by an enzymatic method using the uricaseperoxidase system ${ }^{15)}$.

\section{IVUS Measurement}

We characterized tissue from coronary plaques in culprit lesions in patients with acute coronary syndrome (ACS) or stable angina pectoris. IB-IVUS examinations were performed with the IVUS imaging system (VISIWAVE, Terumo, Tokyo, Japan) and a $40-\mathrm{MHz}, 5$ Fr IVUS imaging catheter (ViewIT ${ }^{\mathrm{TM}}$, Terumo). IB-IVUS images were captured at a speed of $0.5 \mathrm{~mm} / \mathrm{s}$ using a motorized pull-back system. Plaque analysis was performed in the range of culprit lesions at $1-\mathrm{mm}$ axial intervals. Plaque volume was calculated as the sum of plaque plus media in each cross-sectional area. IB data for each tissue component were calcu- 
Table 2. IVUS characteristics

\begin{tabular}{|c|c|c|c|c|c|c|c|c|c|}
\hline & \multicolumn{4}{|c|}{ Male } & \multicolumn{4}{|c|}{ Female } & \multirow{2}{*}{$\begin{array}{c}\text { Interaction } \\
\text { P with } \\
\text { gender }\end{array}$} \\
\hline & $\begin{array}{c}\mathrm{T} 1 \mathrm{M} \\
(n=100)\end{array}$ & $\begin{array}{c}\mathrm{T} 2 \mathrm{M} \\
(n=97)\end{array}$ & $\begin{array}{c}\text { T3M } \\
(n=101)\end{array}$ & $P$ value & $\begin{array}{c}\text { T1F } \\
(n=29)\end{array}$ & $\begin{array}{c}\text { T2F } \\
(n=29)\end{array}$ & $\begin{array}{c}\mathrm{T} 3 \mathrm{~F} \\
(n=29)\end{array}$ & $P$ value & \\
\hline Lesion length, mm & $18.0(13.0-22.0)$ & $15.0(11.7-19.8)$ & $17.5(13.0-24.0)$ & 0.065 & $20.5(12.4-28.0)$ & $17.2(11.1-25.0)$ & $14.0(10.4-24.0)$ & 0.138 & 0.208 \\
\hline Plaque volume, $\mathrm{mm}^{3}$ & $145.0(100.2-193.7)$ & $138.2(97.6-217.2)$ & $148.8(108.0-213.2)$ & 0.175 & $170.6(105.5-219.3)$ & $147.5(88.5-219.7)$ & $114.1(78.7-185.2)$ & 0.224 & 0.084 \\
\hline$\%$ lipid volume & $46.3 \pm 13.4$ & $49.6 \pm 13.8$ & $56.9 \pm 12.9^{\dagger *}$ & $<0.001$ & $47.0 \pm 10.8$ & $45.8 \pm 13.1$ & $55.4 \pm 11.7^{\dagger *}$ & 0.006 & 0.526 \\
\hline$\%$ fibrous volume & $43.8 \pm 9.5$ & $41.7 \pm 9.8$ & $36.6 \pm 9.4^{\dagger \dagger}$ & $<0.001$ & $43.3 \pm 7.0$ & $43.9 \pm 9.3$ & $37.9 \pm 9.0^{\dagger \neq}$ & 0.014 & 0.612 \\
\hline$\%$ dense fibrous volume & $7.4 \pm 4.1$ & $6.5 \pm 4.1$ & $4.9 \pm 3.3^{\dagger \neq}$ & $<0.001$ & $7.1 \pm 3.8$ & $7.7 \pm 3.9$ & $5.1 \pm 2.8^{\dagger *}$ & 0.018 & 0.447 \\
\hline$\%$ calcification volume & $2.5 \pm 2.3$ & $2.2 \pm 2.5$ & $1.5 \pm 1.6^{\dagger}$ & 0.005 & $2.5 \pm 1.8$ & $2.4 \pm 1.8$ & $1.6 \pm 1.6$ & 0.087 & 0.907 \\
\hline
\end{tabular}

Data are expressed as mean \pm standard deviation or median (interquartile range). ${ }^{\dagger} p<0.01$ vs T1. ${ }^{\ddagger} p<0.01$ vs T2.

(\%)

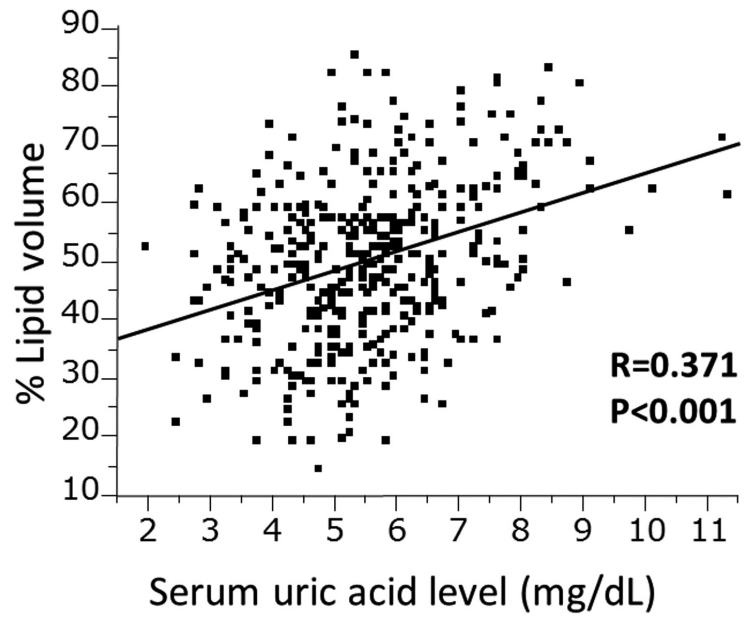

A
(\%)

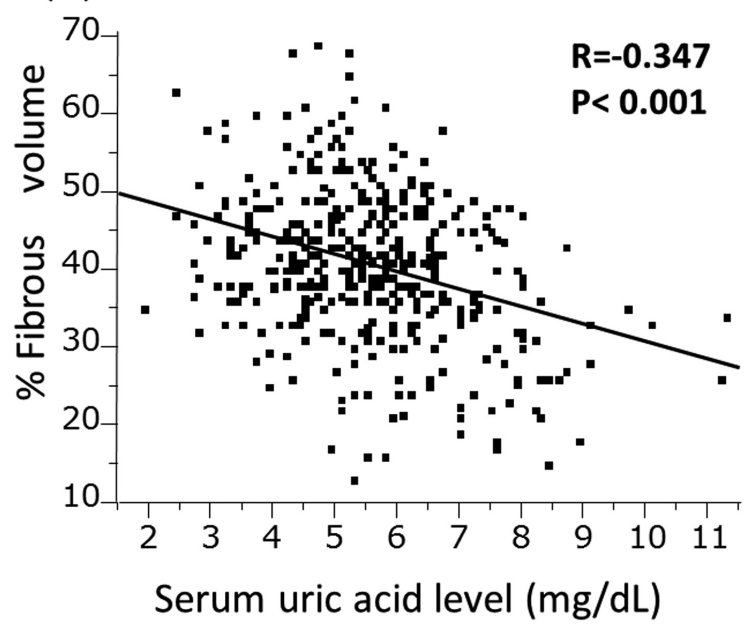

B

Fig. 1. Simple linear regression analysis showing the relationship between serum uric acid levels and coronary plaque components: (A) \% lipid volume and (B) \% fibrous volume.

lated as average power levels using a fast Fourier transform, measured in decibels, of the frequency component of backscattered signals from a small volume of tissue. On the basis of previous data, we applied the manufacturer's default settings of the IB-IVUS ${ }^{13)}$. IBIVUS analysis classified the color-coded tissue into four major components by IB scores measuring backscattered signals from the tissue: blue (lipid), green (fibrosis), yellow (dense fibrosis), and red (calcification ${ }^{16)}$. Quantitative volumetric IB-IVUS analysis was performed to calculate volumes of lipid, fibrosis, dense fibrosis, and calcification from the sum of the areas of the respective tissue types in each cross-sectional area. Then, the percentage volume of each component was calculated: $\%$ lipid volume $=100 \times$ lipid volume/plaque volume, $\%$ fibrous volume $=100 \times$ fibrous volume/ plaque volume, $\%$ dense fibrous volume $=100 \times$ dense fibrosis volume/plaque volume, and \% calcified volume $=100 \times$ calcified volume/plaque volume. Conventional IVUS analysis was performed according to the American College of Cardiology Clinical Expert Consensus Document on Standards for Acquisition, Measurement and Reporting of Intravascular Ultrasound Studies ${ }^{17)}$. Coronary plaques with a lipid area $>65 \%$ have been reported to be associated with the development of $A C S^{13)}$. We defined lipid-rich plaques as having a lipid volume $>65 \%$. It was reported that the percentage of lipid content is different between ACS and stable angina pectoris $(\mathrm{SAP})^{18)}$. Therefore, subgroup analysis that divided the patients into ACS and SAP groups was performed.

\section{Statistical Analysis}

Continuous variables with normal distribution are 
Table 3. Univariate and multivariate logistic analyses for lipid rich plaque

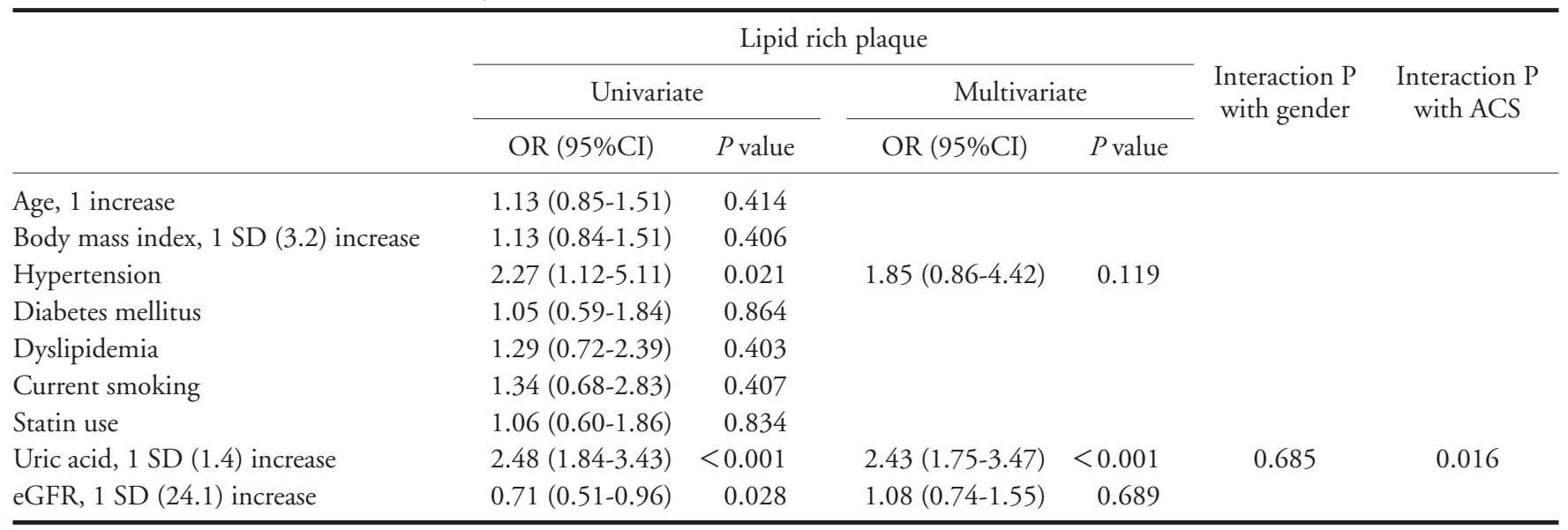

$\mathrm{SD}$, standard deviation; eGFR, estimated glomerular filtration rate; ACS, acute coronary syndrome

presented as the mean \pm SD. Analysis of variance was used for continuous variables, and a chi-square test was used for categorical variables in comparisons between the three groups. When there was statistical significance of differences between the three groups, we performed post-hoc analysis using Tukey's test or the Bonferroni method. Simple linear regression analysis was performed to investigate the relationship between serum uric acid levels and IVUS parameters. Univariate and multivariate logistic analyses were used to identify independent predictors for lipid-rich plaques. Significant predictors selected in the univariate analysis were entered into the multivariate analysis. Interaction test was performed to take account of interaction with each subgroup. A $p$ value $<0.05$ was considered statistically significant. All statistical analyses were performed with a standard statistical program package (JMP version 9.0, SAS Institute Inc., Cary, NC, USA).

\section{Results}

\section{Clinical Characteristics}

Study patients were divided into three groups in each gender according to tertile of serum uric acid level (Male: T1M $<5.0 \mathrm{mg} / \mathrm{dl}, n=100$; T2M 5.0-6.2 $\mathrm{mg} / \mathrm{dl}, n=97 ; \mathrm{T} 3 \mathrm{M}>6.2 \mathrm{mg} / \mathrm{dl}, n=101$. Female: $\mathrm{T} 1 \mathrm{~F}<4.6 \mathrm{mg} / \mathrm{dl}, n=29$; T2F $4.6-5.3 \mathrm{mg} / \mathrm{dl}, n=29$; $\mathrm{T} 3 \mathrm{~F}>5.3 \mathrm{mg} / \mathrm{dl}, n=29)$.

The clinical characteristics of male and female patients are summarized in Table $\mathbf{1}$. There were no significant differences in the prevalence of current smoking, serum cholesterol levels, and left ventricular ejection fraction examined by echocardiography among the three groups in either gender. There were significant differences in body mass index; the prevalence of hypertension, dyslipidemia, and ACS; and the usage of antihyperuricemics between the three groups in males. However, there was no significant interaction with gender. Group T3M had a lower estimated glomerular filtration rate (eGFR) than groups T1M and T2M. Group T3F had a lower eGFR than group $\mathrm{T} 1 \mathrm{~F}$ and had a higher prevalence of diabetes mellitus than group T2F. There were no significant differences in the use of renin-angiotensin aldosterone system inhibitors among the three groups in either gender.

\section{Association between Coronary Plaque Components and Serum Uric Acid Levels}

There were no significant differences in total plaque volume among the three groups in either gender (Table 2). Group T3M and T3F had higher \% lipid volume, and lower \% fibrous and \% dense fibrous volume than the other groups in both genders.

Simple linear regression analysis revealed that serum uric acid levels correlated significantly with \% lipid volume $(r=0.371, p<0.001$; Fig. 1A) and inversely correlated with $\%$ fibrous volume $(r=-0.347, p<$ 0.001; Fig. 1B).

We evaluated the predictors for lipid-rich plaques (Table 3). Univariate analysis showed that hypertension, eGFR, and uric acid levels were significantly associated with lipid-rich plaque formation. In multivariate analysis, the uric acid level was independently associated with the presence of lipid-rich plaques. However, there was interaction between the predictive ability of serum uric acid levels for lipid-rich plaques and ACS. Fig. 2 shows the prevalence rate of lipid-rich plaques in each tertile in both genders. Group T3M had a significantly higher prevalence of lipid-rich plaques than groups T1M and T2M. Groups T2F and $\mathrm{T} 3 \mathrm{~F}$ had a significantly higher prevalence of lipid-rich plaques than group T1F. There was no interaction 


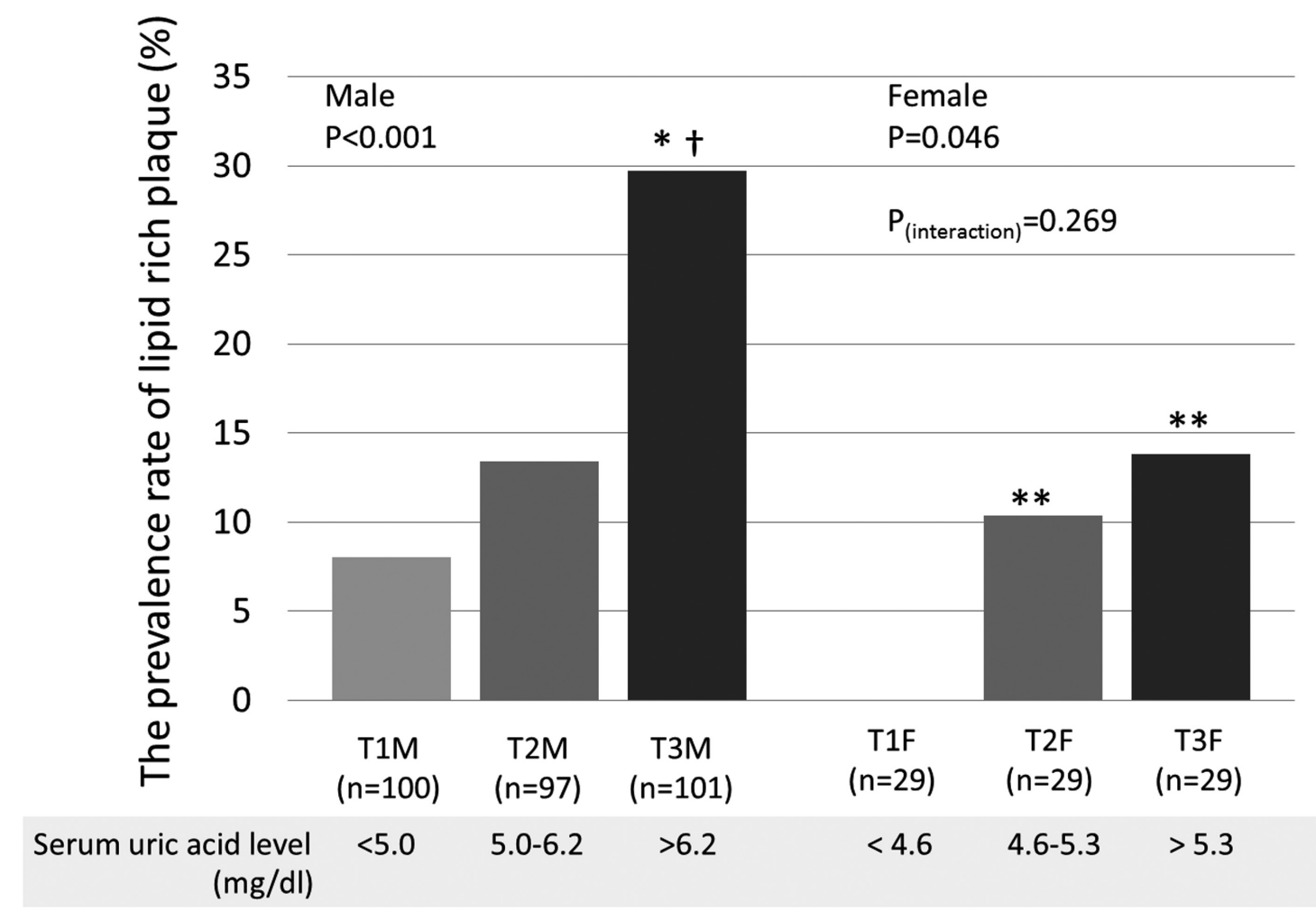

Fig. 2. The prevalence of lipid-rich plaques in each tertile of serum uric acid level in males and females. Study patients were divided into three groups in each gender according to tertile of serum uric acid level (male: T1M, low tertile; T2M, intermediate tertile; T3M, high tertile. Female: T1F, low tertile; T2F, intermediate tertile; T3F, high tertile). ${ }^{*} p<0.01$ vs. T1M; ${ }^{\dagger} p<0.01$ vs. T2M; and ${ }^{* *} p<0.05$ vs. T1F.

with gender (interaction $p=0.269$ ).

There was no significant difference in the prevalence rate of lipid-rich plaques between the three groups in the SAP group $(p=0.084$, interaction $p=0.041$; Fig. 3). However, the prevalence rate of lipid-rich plaques in group T3 in ACS group was significantly greater than that in groups $\mathrm{T} 1$ and $\mathrm{T} 2$.

\section{Discussion}

The present study revealed that elevated serum uric acid levels were associated with higher percentage lipid volume and lower percentage fibrous volume in target coronary plaques. After adjustment for confounding factors, higher serum uric acid levels were independently associated with lipid-rich plaques.

It remains controversial whether asymptomatic hyperuricemia causes cardiovascular disease. Association between serum uric acid levels and coronary artery disease is frequently obscured by other comorbid cardiovascular risk factors such as hypertension, kidney dysfunction, and metabolic syndrome ${ }^{3,19)}$. Several epidemiological cohort studies showed that the impact of hyperuricemia on cardiovascular diseases is greater in females than in males ${ }^{9)}$, and that a modest increase in serum uric acid levels to $\geq 6.0 \mathrm{mg} / \mathrm{dl}$ is associated with cardiovascular disease in females ${ }^{20)}$. It was reported that high concentration of serum uric acid was correlated with coronary endothelial microvascular dysfunction in only women ${ }^{21)}$. Recently, it was reported that elevated serum uric acid levels are associated with lipid-rich plaques ${ }^{6}$. However, they analyzed the relationship between uric acid levels and plaque components without taking account of gender difference in serum uric acid levels. In the present study, the prevalence of lipid-rich plaques increased with increasing serum uric acid levels $(\geq 4.6 \mathrm{mg} / \mathrm{dl})$ in female patients. Japanese guidelines for the treatment of hyperuricemia and gout recommend that the serum uric acid should be $<6.0 \mathrm{mg} / \mathrm{dl}$ in both genders ${ }^{22)}$. A more stringent control of uric acid levels in females may be required.

Verdecchia et al. reported that low serum uric acid, i.e., $<4.5 \mathrm{mg} / \mathrm{dl}$ in males and $<3.2 \mathrm{mg} / \mathrm{dl}$ in females, increased cardiovascular events ${ }^{23)}$. Because uric acid is a potent antioxidant, it has been suggested that the levels of reactive oxygen species may increase when serum uric acid levels decrease significantly ${ }^{24)}$. 


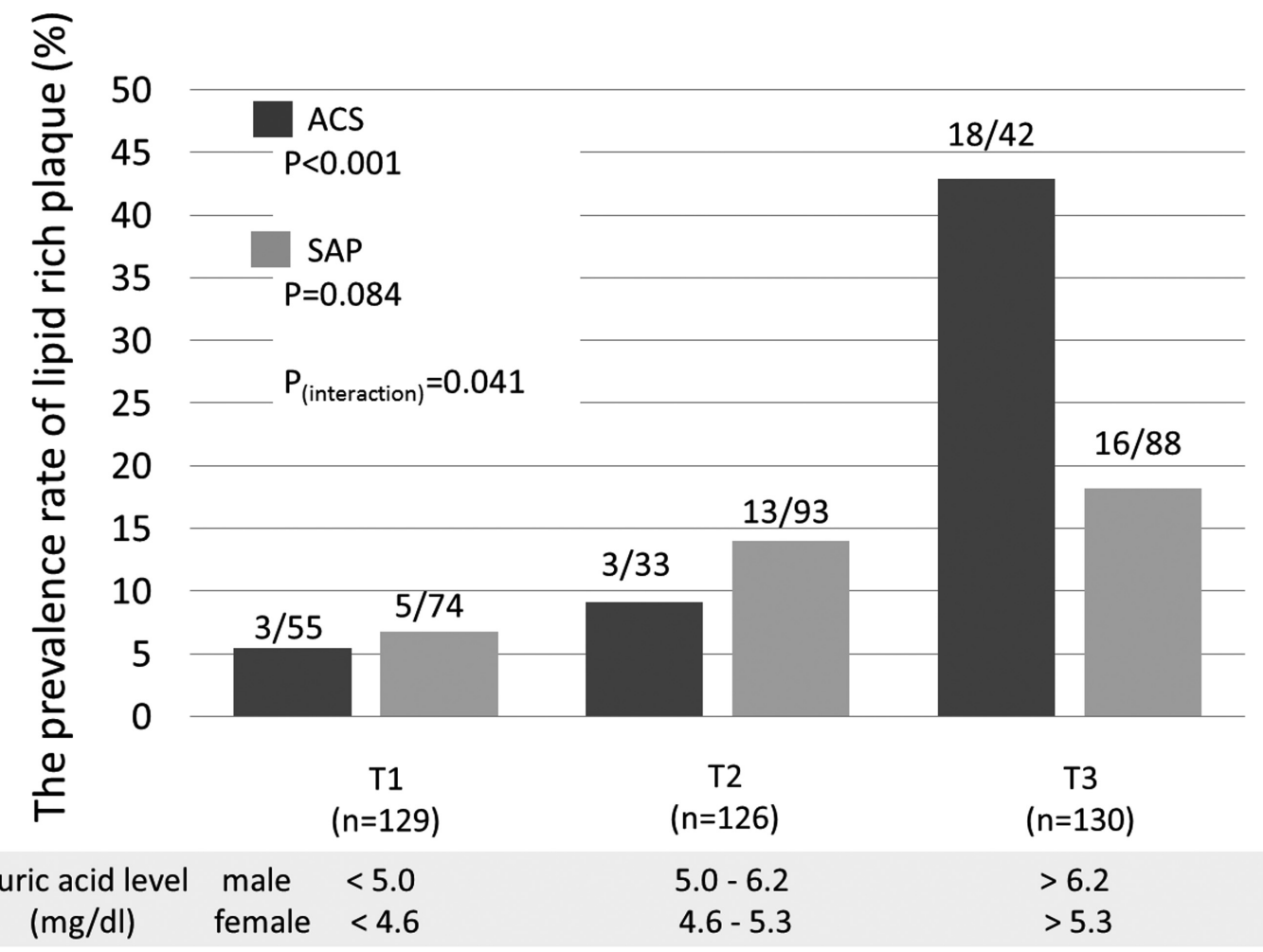

Fig. 3. The prevalence of lipid-rich plaques in each tertile of serum uric acid level in acute coronary syndrome and stable angina pectoris. Patients were divided into three groups according to tertile of serum uric acid level (T1, T1M+T1F; T2, T2M + T2F; T3, T3M+T3F). Data were expressed as number of patients with lipid-rich plaque/number of patients in each subgroup. ACS, acute coronary syndrome; SAP, stable angina pectoris.

However, we did not observe a so-called "J curve" relationship between serum uric acid levels and \% lipid plaque volume in the present study.

Several mechanisms have been proposed for the involvement of hyperuricemia in coronary atherosclerosis. Macrophages infiltrate into injured vascular endothelial cells and form foam cells by the incorporation of oxidized low-density lipoprotein cholesterol or remnants, which facilitate lipid-rich plaque formation $^{25)}$. Hyperuricemia was reported to induce vascular endothelial injury through production of neutrophil extracellular traps ${ }^{26,27)}$. Xanthine oxidoreductase (XOR), which is the rate-limiting enzyme of uric acid production, is reportedly expressed in macrophages ${ }^{28)}$. Lipid accumulation in, and macrophage infiltration into, injured vascular endothelia are inhibited by XOR inhibitors $^{29,30)}$. Activated XOR may promote atherosclerotic plaque formation through lipid accumulation into the plaque. Recently, XOR was reported to promote macrophage interleukin- $1 \beta$ secretion via activation of the NOD-like family receptor, pyrin domaincontaining 3 inflammasome ${ }^{31}$. It was reported that uric acid can induce smooth muscle proliferation ${ }^{32,33)}$, free radical formation ${ }^{34)}$, and oxidative stress ${ }^{35)}$, which all play roles in the development of arteriosclerosis. However, the causal relationship between hyperuricemia and coronary artery disease is still unclear. There are no criteria for treatment of asymptomatic hyperuricemia to prevent coronary artery disease. In the present study, we showed that elevated serum uric acid was associated with lipid-rich plaque in both genders.

\section{Clinical Implication}

It is still unknown whether lowering serum uric acid levels will provide stabilizing effect on coronary plaques. However, because a smaller increase in serum uric acid levels is associated with lipid-rich plaques in females than in males, more stringent control may be needed to reduce future cardiovascular events in females. Moreover, because it was reported that nonculprit coronary lesions with ACS patients are associated with the lipid-rich plaques ${ }^{18)}$, lowering serum uric acid may be beneficial for secondary prevention in patients with hyperuricemia who underwent PCI. 


\section{Limitations}

The present study has several limitations. First, it was performed in only one medical center. A randomized controlled multicenter study is required to investigate the causal relationship between hyperuricemia and coronary artery disease. Second, we considered lipid-rich plaque to be vulnerable plaque, but several other factors are related to plaque vulnerability ${ }^{36}$. Third, predictive ability of serum uric acid levels for lipid-rich plaque was qualified only in patients with ACS. Further prospective study is needed to reveal the impact of serum uric acid on lipid-rich plaque in SAP.

\section{Conclusion}

Increased serum uric acid levels were associated with larger lipid content and smaller fibrosis of coronary plaques, as assessed by IB-IVUS in both genders. Lipid-rich plaque was associated with higher serum uric acid levels, particularly in patients with ACS. Lowering serum uric acid levels may be an option to stabilize vulnerable coronary plaques.

\section{Conflicts of Interest Statement} declare.

The authors have no conflicts of interest to

\section{References}

1) Gertler MM, Garn SM, Levine SA. Serum uric acid in relation to age and physique in health and in coronary heart disease. Ann Intern Med 1951; 34: 1421-1431

2) Fang J, Alderman MH. Serum uric acid and cardiovascular mortality the NHANES I epidemiologic follow-up study, 1971-1992. National Health and Nutrition Examination Survey. JAMA 2000; 283: 2404-2410

3) Culleton BF, Larson MG, Kannel WB, Levy D. Serum uric acid and risk for cardiovascular disease and death: the Framingham Heart Study. Ann Intern Med 1999; 131: 7-13

4) Nozue $T$, Yamamoto $S$, Tohyama $S$, Fukui K, Umezawa $S$, Onishi Y, Kunishima T, Hibi K, Terashima M, Michishita I. Correlations between serum uric acid and coronary atherosclerosis before and during statin therapy. Coron Artery Dis 2014; 25: 343-348

5) Kaya EB, Yorgun H, Canpolat U, Hazirolan T, Sunman H, Ülgen A, Ates AH, Aytemir K, Tokgözoğlu L, Kabakcı G, Akata D, Oto A. Serum uric acid levels predict the severity and morphology of coronary atherosclerosis detected by multidetector computed tomography. Atherosclerosis 2010; 213: 178-183

6) Saito Y, Nakayama T, Sugimoto K, Fujimoto Y, Kobayashi Y. Relation of Lipid Content of Coronary Plaque to Level of Serum Uric Acid. Am J Cardiol 2015; 116: 1346-1350

7) Adamopoulos D, Vlassopoulos C, Seitanides B, Contoyi- annis P, Vassilopoulos P. The relationship of sex steroids to uric acid levels in plasma and urine. Acta Endocrinol (Copenh) 1977; 85: 198-208

8) Dincer HE, Dincer AP, Levinson DJ. Asymptomatic hyperuricemia: to treat or not to treat. Cleve Clin J Med 2002; 69: 594, 597, 600-602 passim

9) Strasak AM, Kelleher CC, Brant LJ, Rapp K, Ruttmann E, Concin H, Diem G, Pfeiffer KP, Ulmer H; VHM\&PP Study Group. Serum uric acid is an independent predictor for all major forms of cardiovascular death in 28,613 elderly women: a prospective 21-year follow-up study. Int J Cardiol 2008; 125: 232-239

10) Sun Y, Yu X, Zhi Y, Geng S, Li H, Liu T, Xu K, Chen L, Wu C, Qi G. A cross-sectional analysis of the relationship between uric acid and coronary atherosclerosis in patients with suspected coronary artery disease in China. BMC Cardiovasc Disord 2014; 14: 101

11) Okubo M, Kawasaki M, Ishihara $Y$, Takeyama U, Kubota T, Yamaki T, Ojio S, Nishigaki K, Takemura G, Saio M, Takami T, Minatoguchi S, Fujiwara H. Development of integrated backscatter intravascular ultrasound for tissue characterization of coronary plaques. Ultrasound Med 2008; 34: 655-663

12) Kawasaki M, Takatsu H, Noda T, Sano K, Ito Y, Hayakawa K, Tuchiya K, Arai M, Nishigaki K, Takemura G, Minatoguchi S, Fujiwara T, Fujiwara H. In vivo quantitative tissue characterization of human coronary arterial plaques by use of integrated backscatter intravascular ultrasound and comparison with angioscopic findings. Circulation 2002; 105: 2487-2492

13) Sano K, Kawasaki M, Ishihara $Y$, Okubo M, Tsuchiya K, Nishigaki K, Zhou X, Minatoguchi S, Fujita H, Fujiwara $\mathrm{H}$. Assessment of vulnerable plaques causing acute coronary syndrome using integrated backscatter intravascular ultrasound. J Am Coll Cardiol 2006; 47: 734-741

14) Daidoji H, Takahashi H, Otaki Y, Tamura H, Arimoto T, Shishido T, Miyashita T, Miyamoto T, Watanabe T, Kubota I. A combination of plaque components analyzed by integrated backscatter intravascular ultrasound and serum pregnancy-associated plasma protein A levels predict the no-reflow phenomenon during percutaneous coronary intervention. Catheter Cardiovasc Interv 2015; 85: 43-50

15) Gochman N, Schmitz JM. Automated determination of uric acid, with use of a uricase-peroxidase system. Clin Chem 1997; 17: 1154-1159

16) Okubo M, Kawasaki M, Ishihara $Y$, Takeyama U, Yasuda S, Kubota T, Tanaka S, Yamaki T, Ojio S, Nishigaki K, Takemura G, Saio M, Takami T, Fujiwara H, Minatoguchi S. Tissue characterization of coronary plaques: comparison of integrated backscatter intravascular ultrasound with virtual histology intravascular ultrasound. Circ J 2008; 72: 1631-1639

17) Mintz GS, Nissen SE, Anderson WD, Bailey SR, Erbel R, Fitzqerald PJ, Pinto FJ, Rosenfield K, Sieqel RJ, Tuzcu EM, Yock PG. American College of Cardiology Clinical Expert Consensus Document on Standards for Acquisition, Measurement and Reporting of Intravascular Ultrasound Studies (IVUS). A report of the American College of Cardiology Task Force on Clinical Expert Consensus Documents. J Am Coll Cardiol. 2001; 37: 1478-1492 
18) Ando H, Amano T, Matsubara T, Uetani T, Nanki M, Marui N, Kato M, Yoshida T, Yokoi K, Kumagai S, Isobe $\mathrm{S}$, Ishii $\mathrm{H}$, Izawa $\mathrm{H}$, Murohara T. Comparison of tissue characteristics between acute coronary syndrome and stable angina pectoris. An integrated backscatter intravascular ultrasound analysis of culprit and non-culprit lesions. Circ J 2011; 75: 383-390

19) Bengtsson C, Lapidus L, Stendahl C, Waldenstrom J. Hyperuricemia and risk of cardiovascular disease and overall death: a 12-year follow-up of participants in the population study of women in Gothenburg, Sweden. Acta Med Scand 1988; 224: 549-555

20) Hakoda M, Masunari N, Yamada M, Fujiwara S, Suzuki G, Kodama K, Kasagi F. Serum uric acid concentration as a risk factor for cardiovascular mortality: a longterm cohort study of atomic bomb survivors. J Rheumatol 2005; 32: 906-912

21) Kuwahata S, Hamasaki S, Ishida S, Kataoka T, Yoshikawa A, Orihara K, Ogawa M, Oketani N, Saihara K, Okui H, Shinsato T, Kubozono T, Ichiki H, Fujita S, Takumi T, Yoshino S, Nakazaki M, Miyata M, Tei C. Effect of uric acid on coronary microvascular endothelial function in women: association with eGFR and ADMA. J Atheroscler Thromb 2010; 17: 259-269

22) Guideline for the management of hyperuricemia and gout. 2nd edition. The Guideline revising committee of Japanese Society of Gout Nucleic Acid Metabolism. Gout and Nucleic Acid Metabolism 2010; 34: 109-144

23) Verdecchia,P, Schillaci G, Reboldi G, Santeusanio F, Porcellati C, Brunetti P. Relationship between serum uric acid and risk of cardiovascular disease in essential hypertension. The PIUMA study. Hypertention 2000; 36: 1072-1078

24) Waring WS, Webb DJ, Maxwell SR. Systemic uric acid administration increases serum antioxidant capacity in healthy volunteers. J Cardiovasc Pharmacol 2001; 38: 365-371

25) Ishigaki Y, Katagiri H, Gao J, Yamada T, Imai J, Uno K, Hasegawa Y, Kaneko K, Ogihara T, Ishihara H, Sato Y, Takikawa K, Nishimichi N, Matsuda H, Sawamura T, Oka Y. Impact of plasma oxidized low-density lipoprotein removal on atherosclerosis. Circulation 2008; 118: 75-83

26) Kanbay M, Yilmaz MI, Sonmez A, Turgut F, Saglam M, Cakir E, Yenicesu M, Covic A, Jalal D, Johnson RJ. Serum uric acid level and endothelial dysfunction in patients with nondiabetic chronic kidney disease. Am J Nephrol 2011; 33: 298-304

27) Arai Y, Nishinaka Y, Arai T, Morita M, Mizugishi K, Adachi S, Takaori-Kondo A, Watanabe T, Yamashita K. Uric acid induces NADPH oxidase-independent neutrophil extracellular trap formation. Biochem Biophys Res Commun 2014; 443: 556-561
28) Moriwaki Y, Yamamoto T, Suda M, Nasako Y, Takahashi S, Agbedana OE, Hada T, Higashino K. Purification and immunohistochemical tissue localization of human xanthine oxidase. Biochim Biophys Acta 1993; 1164: 327-330

29) Nomura J, Busso N, Ives A, Matsui C, Tsujimoto S, Shirakura T, Tamura M, Kobayashi T, So A, Yamanaka Y. Xanthine oxidase inhibition by febuxostat attenuates experimental atherosclerosis in mice. Sci Rep 2014; 4: 4554

30) Kushiyama A, Okubo H, Sakoda H, Kikuchi T, Fujishiro M, Sato H, Kushiyama S, Iwashita M, Nishimura F, Fukushima T, Nakatsu Y, Kamata H, Kawazu S, Higashi Y, Kurihara H, Asano T. Xanthine oxidoreductase is involved in macrophage foam cell formation and atherosclerosis development. Arteriocler Thromb Vasc Biol 2012; 32: 291-298

31) Ives A, Nomura J, Martinon F, Roger T, LeRoy D, Miner JN, Simon G, Busso N, So A. Xanthine oxidoreductase regulates macrophage IL1 $\beta$ secretion upon NLRP3 inflammasome activation. Nat Commun 2015. DOI: 10.1038/ ncomms 7555

32) Rao GN, Corson MA, Berk BC. Uric acid stimulates vascular smooth muscle cell proliferation by increasing platelet-derived growth factor A-chain expression. J Biol Chem 1991; 266: 8604-8608

33) Watanabe $S$, Kang DH, Feng K, Nakagawa T, Kanellis J, Mazzali M, Johnson RJ. Uric acid, hominoid evolution, and the pathogenesis of salt-sensitivity. Hypertension 2002; 40: 355-360

34) Vasquez-Vivar J, Santos AM, Junqueira VB, Augusto O. Peroxynitritemediated formation of free radicals in human plasma: EPR detection of ascorbyl, albumin-thiyl and uric acid-derived free radicals. Biochem J 1996; 314: 869-876

35) Leyva F, Anker S, Swan JW, Godsland IF, Wingrove CS, Chua TP, Stevenson JC, Coats AJ. Serum uric acid as an index of impaired oxidative metabolism in chronic heart failure. Eur Heart J 1997; 18: 858-886

36) Naghavi M1, Libby P, Falk E, Casscells SW, Litovsky S, Rumberger J, Badimon JJ, Stefanadis C, Moreno P, Pasterkamp G, Fayad Z, Stone PH, Waxman S, Raggi P, Madjid M, Zarrabi A, Burke A, Yuan C, Fitzgerald PJ, Siscovick DS, de Korte CL, Aikawa M, Juhani Airaksinen KE, Assmann G, Becker CR, Chesebro JH, Farb A, Galis ZS, Jackson C, Jang IK, Koenig W, Lodder RA, March K, Demirovic J, Navab M, Priori SG, Rekhter MD, Bahr R, Grundy SM, Mehran R, Colombo A, Boerwinkle E, Ballantyne C, Insull W Jr, Schwartz RS, Vogel R, Serruys PW, Hansson GK, Faxon DP, Kaul S, Drexler H, Greenland P, Muller JE, Virmani R, Ridker PM, Zipes DP, Shah $\mathrm{PK}$, Willerson JT.From vulnerable plaque to vulnerable patient: a call for new definitions and risk assessmentstrategies: Part I. Circulation 2003; 108: 1664-1672 